\title{
Mathematical simulation of the forest fire thermal effect on root system fragments of coniferous tree
}

\author{
Nikolay Baranovskiy ${ }^{1, *}$, Dmitry Zakovryashin ${ }^{1 *}$ \\ ${ }^{1}$ National Research Tomsk Polytechnic University, 634050 Tomsk, Russia
}

\begin{abstract}
We present the numerical simulation results of heat transfer in a layered structure of the root branch when exposed to a high temperature from a forest fire in this paper. The problem is solved by the method of finite differences in a cylindrical coordinate system using a onedimensional formulation. Typical exposure times and temperatures in the forest fire front are considered. The temperature distributions are presented for the system "root fragment-soil-forest fuel-air". We revealed the character of the temperature distribution and the depth of the soil layer heating to the values which are dangerous for the coniferous tree root system.
\end{abstract}

\section{Introduction}

Analyzing the events of recent decades, we can say that forest fires have turned from a natural regulatory factor into catastrophic phenomena leading to environmental, economic and social damage $[1,2]$. High temperatures of forest fires have a negative impact on forest stands, leading to their damage and even death $[3,4]$. Besides predicting forest fire danger [5], it is extremely important to develop technologies that predict the damage caused by forest fires to stands.

At present, there are a lot of papers devoted to the analysis of statistics of forest fires in the context of their environmental impact [6]. There are a number of articles devoted to the mathematical modeling of heat transfer in soil [7] during a forest fire, however, only the depth of warming up the soil layer to temperatures lethal for microorganisms living in the soil considered in this work. At the same time, many articles have been published to date, describing the results of full-scale studies of the effect of forest fires on the soil, which make it possible to estimate the temperature of warming up the soil layer to the marks dangerous for the roots of trees $[8,9]$. Despite this, creation of computer systems for geoecological monitoring of forest areas exposed to forest fires, based on physically meaningful mathematical models of heat transfer, the should become the main direction of development.

The purpose of this work is a numerical study of heat transfer in the structure of the root fragment of a coniferous tree exposed to high temperature from a forest fire.

${ }^{*}$ Corresponding author: firedanger@tpu.ru 


\section{Mathematical model}

Fig. 1. presents photo of bare root of a coniferous tree. The roots of these tree species mainly located at a depth of $0,2 \mathrm{~m}$. The pronounced root is absent, the core root is not deep, the greater part of the root system grows in the near-surface layer of the soil and extends not inland, but in the sides, occupying an area of up to $47 \mathrm{~m}^{2}$. These circumstances make the roots of coniferous trees such as spruce, pine and cedar very sensitive to the effects of grassland forest fires.

To study the processes of heat transfer, we consider a separate fragment of the root, lying at a depth of $0.2 \mathrm{~m}$, located horizontally with respect to the soil surface.

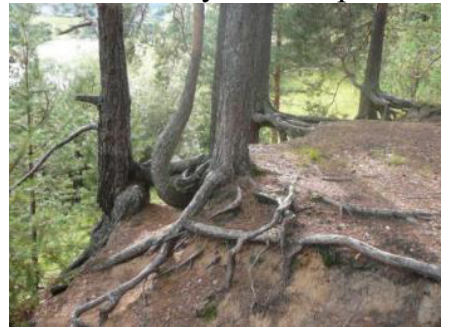

Fig. 1. The root of the coniferous tree.

The boundary-value problem of conductive heat transfer in the conjugate formulation is considered. The geometry of the solution area shown in Fig. 2.

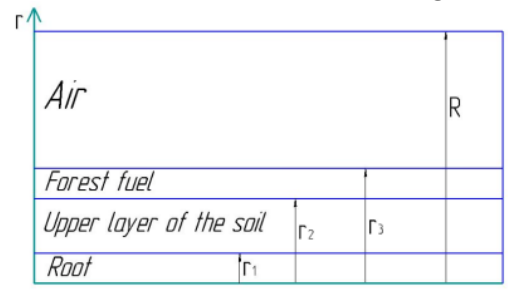

Fig. 2. The solution area.

The solution region is represented as a layered structure: core, a layer rich in organic matter, a layer of forest combustible material on the surface of the soil (subject to combustion), and a layer of ambient air. Boundary conditions of the 4th kind are set on the media interfaces. A high temperature corresponding to the a grass-roots fire is given in the layer of forest combustible material.

The following assumptions accepted: the thermophysical properties of the organic layer of the soil, the layer of forest fuel and air do not depend on temperature, heat transfer in the air is due to conduction.

According to the proposed physical model, the process under investigation is described by nonstationary heat conduction equations for each element of the solution area:

- Heat transfer equation for the root of a tree.

$$
\rho_{1} c_{1} \frac{\partial T_{1}}{\partial t}=\frac{\lambda_{1}}{r} \frac{\partial}{\partial r}\left(r \frac{\partial T_{1}}{\partial r}\right)
$$

- Heat transfer equation for the organic layer of the soil.

$$
\rho_{2} c_{2} \frac{\partial T_{2}}{\partial t}=\frac{\lambda_{2}}{r} \frac{\partial}{\partial r}\left(r \frac{\partial T_{2}}{\partial r}\right)
$$


- Heat transfer equation for the forest fuel layer.

$$
\rho_{3} c_{3} \frac{\partial T_{3}}{\partial t}=\frac{\lambda_{3}}{r} \frac{\partial}{\partial r}\left(r \frac{\partial T_{3}}{\partial r}\right)
$$

- Heat transfer equation for the layer of ambient air.

$$
\rho_{4} c_{4} \frac{\partial T_{4}}{\partial t}=\frac{\lambda_{4}}{r} \frac{\partial}{\partial r}\left(r \frac{\partial T_{4}}{\partial r}\right)
$$

The initial conditions for equations (1) - (4) defined as:

$$
\left.T_{i}\right|_{t=0}=T_{i 0}
$$

The boundary conditions for equations (1) - (4) defined as:

- On the outer boundaries of the solution area.

$$
\begin{gathered}
r=R,-\lambda_{4} \frac{\partial T_{4}}{\partial r}=\alpha_{4}\left(T_{e}-T_{4}\right) \\
r=0,-\lambda_{1} \frac{\partial T_{1}}{\partial r}=0
\end{gathered}
$$

- On the interfaces of the layers.

$$
\begin{aligned}
& r=r_{3},-\lambda_{3} \frac{\partial T_{3}}{\partial r}=-\lambda_{4} \frac{\partial T_{4}}{\partial r}, T_{3}=T_{4} \\
& r=r_{2},-\lambda_{2} \frac{\partial T_{2}}{\partial r}=-\lambda_{3} \frac{\partial T_{3}}{\partial r}, T_{2}=T_{3} \\
& r=r_{1},-\lambda_{1} \frac{\partial T_{1}}{\partial r}=-\lambda_{2} \frac{\partial T_{2}}{\partial r}, T_{1}=T_{2}
\end{aligned}
$$

where $T_{i}, c_{i}, \rho_{i}, \lambda_{i}, r_{i}$ - temperature, heat capacity, density, heat conductivity, coordinate along the axis $r$ (1 - root, 2 - soil layer, 3 - forest fuel layer, 4 - air layer); $\alpha_{4}$ - heat transfer coefficient; $t$ - time coordinate.

In the numerical simulation, the following initial data were used: $\rho_{1}=520 \mathrm{~kg} / \mathrm{m}^{3}$, $\rho_{2}=1070 \mathrm{~kg} / \mathrm{m}^{3}, \quad \rho_{3}=500 \mathrm{~kg} / \mathrm{m}^{3}, \quad \rho_{4}=0,03 \mathrm{~kg} / \mathrm{m}^{3}, \quad c_{1}=2700 \mathrm{~J} / \mathrm{kg} \cdot \mathrm{K}$, $c_{2}=976 \mathrm{~J} / \mathrm{kg} \cdot \mathrm{K}, \quad c_{3}=1400 \mathrm{~J} / \mathrm{kg} \cdot \mathrm{K}, \quad c_{4}=1200 \mathrm{~J} / \mathrm{kg} \cdot \mathrm{K}, \quad \lambda_{1}=0,11 \mathrm{~W} / \mathrm{m} \cdot \mathrm{K}$, $\lambda_{2}=0,5 \mathrm{~W} / \mathrm{m} \cdot \mathrm{K}, \lambda_{3}=0,102 \mathrm{~W} / \mathrm{m} \cdot \mathrm{K}, \lambda_{4}=0,1 \mathrm{~W} / \mathrm{m} \cdot \mathrm{K}, \alpha_{4}=80 \mathrm{~W} / \mathrm{m}^{2} \cdot \mathrm{K}$.

\section{Results and discussion}


Currently, forest fires divided into several types, each of them characterized by a certain temperature in the area of the combustion. In this paper, a high temperature in the forest fuel layer equal to $1073 \mathrm{~K}$ assigned to simulate the process of heating from the focus of forest fire, which according to the classification of forest fires corresponds to the temperature of the surface forest fire. This type of forest fire chosen for modeling due to the prevalence.

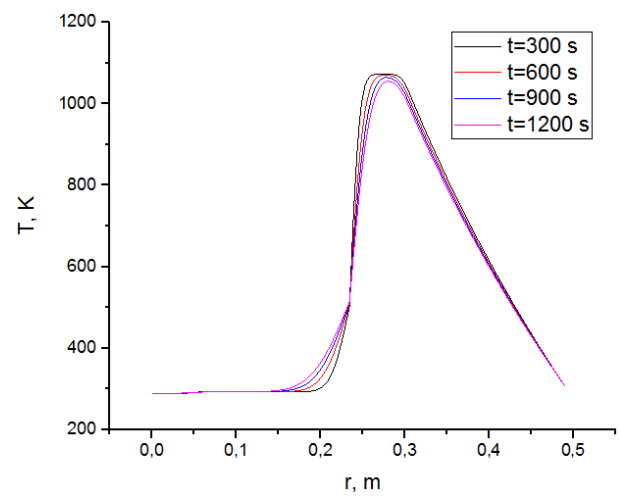

Fig. 2. Distribution of temperatures in the "root-soil-forest fuel-air" system at different time of exposure to the fire.

This task solved by the method of finite differences [10,11]. The double-sweep method used to solve finite-difference analogues. Fig. 2. shows the temperature distribution in the "root - soil - forest fuel - air" system, Fig. 3. presents distribution in "root-soil" system with an exposure time of $300 \mathrm{~s}, 600 \mathrm{~s}, 900 \mathrm{~s}$, and $1200 \mathrm{~s}$. Fig. 3. shows that lethal for the root system a value of temperature $330 \mathrm{~K}$ observed at a depth of the soil layer equal $0,08 \mathrm{~m}$ at a maximum exposure time $1200 \mathrm{~s}$, while the root of the tree lies at a depth of $0,2 \mathrm{~m}$. According to this, we can say that the forest fire does not affect the roots located deeper than $0,08 \mathrm{~m}$ and is safety to the stand in terms of thermal damage to the roots.

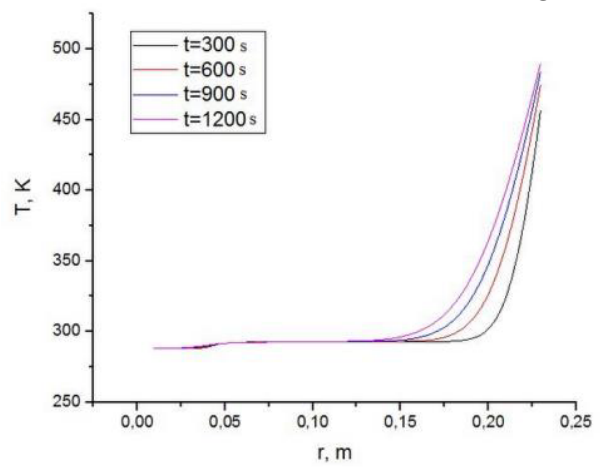

Fig. 3. Distribution of temperatures in the "root-soil" system at different time of exposure to the fire.

\section{Conclusions}

A simplified one-dimensional mathematical model presented to assess the effect of forest fire on a root fragment. A layered structure consisting of a separate root fragment of a coniferous tree, a soil layer, a forest fuel layer and an air layer is considered. The temperature distributions in the "root-soil-forest fuel-air" system obtained for different exposure times of the surface forest fire: $300 \mathrm{~s}, 600 \mathrm{~s}, 900 \mathrm{~s}, 1200 \mathrm{~s}$. A high temperature $1073 \mathrm{~K}$ established in the forest fuel layer to simulate the heating process. It is found that 
the lethal value of temperature for the tree root observed at a maximum depth of $0.08 \mathrm{~m}$. The obtained data are in qualitative agreement with field observations. In the future, the results of this work can be used to create systems for geo-ecological monitoring of forest areas with the aim of predicting mortality and fragmentation of forest stands after forest fires.

The work was supported by the Russian President's grant (Scientific School project 7538.2016.8).

\section{References}

1. G.M. Byram, Combustion of forest fuels, Forest fire control and use (McGraw-Hill, N.Y., 1959)

2. D.V. Korobkina, N.V. Baranovsky, Cloud of Science, 1 (2014)

3. W.F. Laurance, P. Delamonica, S.G. Laurance, H.V. asconcelos, T.E. Lovejoy, Nature, 404 (2000)

4. R.C.G. Mesquita, P. Delamonica, W.F. Laurance, Biological Conservation, 91 (1999)

5. E.P. Yankovich, N.V. Baranovskiy, K.S. Yankovich, IFOST (2014)

6. J.Barlow, C.A.Peres, Biological sciences, 359 (2004)

7. N.V. Baranovsky, A.E. Nee, Engineering Physics and Thermophysics, 87 (2014)

8. E.N.Krasnoshchekova, I.V.Kosov, G.A.Ivanova, Conifers of boreal zone, 3-4 (2008) [In Russian]

9. E.N. Valendik, I.V. Kosov, Forestry, 5 (2008) [In Russian]

10. A.A. Samarskii, P.N. Vabishchevich, Computational Heat Transfer. Mathematical Modelling. (Wiley, Chichester, 1995)

11. A.A.Samarskii, P.N.Vabishchevich Computational Heat Transfer. The Finite Difference Method. Vol. 2 (Wiley, Chichester, 1995) 